\title{
The case for an essential medicines list for Canada
}

\author{
Gina Eom PhD, Paul Grootendorst PhD, Jacalyn Duffin MD PhD
}

$\mathrm{U}$ nlike 117 other member countries of the World Health Organization (WHO), Canada has no essential medicines list. ${ }^{1}$ Many might argue that Canada, as a wealthy country, has no need of one. Should all countries have lists of priority medications that ought to be reliably available, or is this an idea only for countries with less well-developed health systems? Given recent high-profile drug shortages in Canada and strong advocacy for a national pharmacare program, we believe that Canada should have an essential medicines list. At the time of the drug shortage crisis in 2012, the House of Commons Standing Committee on Health recommended that Canada establish an essential medicines list as soon as possible. ${ }^{2}$

\section{What is an essential medicines list?}

An essential medicines list includes 200-500 medicines (which could include prescription drugs, over-the-counter drugs and natural health products) that a government commits to keep in stock. Medicines that appear in the list are chosen on the basis of drug safety, effectiveness and cost. The judicious selection of medicines for the list is intended to, at once, improve prescribing appropriateness and manage drug spending.

Having an essential medicines list does not necessarily imply that a government must pay for these drugs, although it might. Instead, governments would ensure availability of a core set of drugs needed to treat or manage a variety of important health problems. The list would aim to mitigate drug shortages, guide the development of pharmacare programs and help physician prescribing.

In the 1970s, a period of rapid growth in the number and cost of new pharmaceutical drugs, prescribers treating common health problems could choose from a large array of medicines, the prices of which varied substantially. Physicians found it difficult to keep abreast of the therapeutic properties of all available drugs used to treat the same condition, which led to suboptimal and inappropriate drug use., Maintaining unexpired stocks of each drug became difficult. In 1977, WHO established an initial, general list of 207 drugs for use by national authorities in selecting essential medicines on the basis of efficacy and cost. The aim of having an essential medicines list was to enhance access to crucial treatments by ensuring national supplies in keeping with the access goals of the 1978 Declaration of Alma-Ata. ${ }^{5-7}$ Over time, modifications were made. By 1999, WHO insisted on evidence of efficacy for additions or deletions. Three years later, the original word "drugs" had changed to "medicines" to capture the notion that not all efficacious remedies were pharmaceuticals. By 2011, the number of products on the WHO general list had increased to 358 (445 counting duplicates). The World Health Organization's expert panel follows guidelines on establishing and maintaining essential medicines lists. ${ }^{8}$ The lists are flexible, modified for regional needs and financial resources, and revised every two years as needed.

\section{What is the difference between an essential medicines list and a formulary?}

Essential medicines list and formulary are terms that are sometimes used interchangeably. For example, the WHO website refers to the essential medicines list-associated concept of "model formulary." However, there are important differences between the two. A formulary includes what can be available and how occupants of a particular sphere might acquire or make it. Sometimes the term formulary represents a list of drugs that a drug plan will cover and the conditions under which it will pay for them; a drug not listed on the formulary is not reimbursed. Furthermore, formularies may be kept private or

\section{KEY POINTS}

- Unlike 117 other member countries of the World Health Organization, Canada has no essential medicines list.

- Essential medicines lists have helped to improve access to pharmaceuticals in developing nations; they can also play a role in controlling costs.

- Essential medicines lists could also be a key component of a Canadian national pharmacare plan.
Competing interests: None declared.

This article has been peer reviewed.

Correspondence to: Jacalyn Duffin,duffinj@ queensu.ca /cmaj.160134
CMAJ 2016. DOI:10.1503 
secret. A US survey in 1993 found that none of the representatives of 29 academic health centres viewed their selection system as "open." $\mathrm{In}$ contrast, an essential medicines list declares what must be available nationally and does so openly and organically with regular modifications. The presence of an essential medicines list does not necessarily imply reimbursement, merely assurance of availability.

\section{Are essential medicines lists and like policies effective?}

Rigorous data are lacking. Pharmacoepidemiologic studies analyzing public records for policy implementation, drug availability and drug uses have shown that essential medicines lists are associated with improved availability and quality use of medicines, particularly in lowand middle-income countries. ${ }^{4,10-12}$

For example, South Africa drafted an essential medicines list in 1995, guaranteeing availability and thereby ensuring the improved distribution of $85 \%$ of its key medicines to primary care centres. ${ }^{13}$ Similarly, the Palestinian Ministry of Health created an essential medicines list in 2000 and observed significant improvement in several health indicators, such as quality use of medicines for antibiotics, injectables and numbers of medicines per encounter, and rational choice selection from the essential medicines list. ${ }^{14}$ After facing chronic drug shortages, India used an essential medicines list to enable bulk purchasing of medicines in 2000, achieving an estimated 30\% savings on its annual medicines expenditures, with $70 \%-95 \%$ of patients receiving these medicines..$^{15}$ Nevertheless, these countries continue to experience some regional drug shortages, and errors arise from poor maintenance of the lists; it is not clear how much the essential medicines lists have helped with access to essential treatment overall. ${ }^{16,17}$ China started to rely heavily on its essential medicines list from 2009 as expansion of health insurance coverage and reimbursement levels increased. Medicines on its list were substantially lower in cost than others, partly imposed by price ceilings to ensure affordability, although some suggest that the policies could go further. ${ }^{18,19}$

Wealthier countries have also reaped benefits from purchasing drugs guided by lists similar to essential medicines lists, and substantial cost savings have been reported. For example, since 1928, Norway has maintained an equivalent list of medicines for reimbursement and stockage chosen on the basis of efficacy, qual- ity, safety and cost; a decade later "need" was introduced..$^{20,21}$ Few shortages have been reported in that country.

Australia's National Medicines Policy, launched in 2000, outlined a mechanism for identifying medicines that could be subsidized through the Pharmaceutical Benefits Scheme. The selection mechanism follows an evaluation process similar to that recommended by WHO, cost-effectiveness representing the first step. In Australia, the main goal is to identify medicines eligible for subsidy through the Pharmaceutical Benefits Scheme, predicated on the notion that investing in medicines is a way of controlling illness and costs of uncontrolled illness, which can lead to far greater expenses. Although the amounts spent have increased over time, the prescription drug share of total health care spending has declined. ${ }^{22}$

Sweden made changes to its drug payment system in 2002 out of concerns about rising costs and effectiveness of medications. Patients are responsible for a small copayment (capped at an annual maximum), and the national list of drugs eligible for reimbursement is developed through analysis of cost-effectiveness. ${ }^{23} \mathrm{~A}$ "wise list" of 200 drugs has been used in the Stockholm area for more than 20 years. The list follows a consistent and transparent selection procedure, and it is regularly revised. Practitioners have been shown to trust and adhere to the list when prescribing. The main benefits are cost savings and improved quality of care through more appropriate use of drugs. ${ }^{24}$

New Zealand uses sole source tendering to obtain low prices for formulary drugs. Recognizing its vulnerability to shortages because of its small population, isolation and lack of local manufacturing, New Zealand requires vendors to guarantee availability and provide advance notice of anticipated shortages. Vendors that fail to supply the market face financial penalties. ${ }^{25}$ This energetic vigilance is applied to the New Zealand Pharmaceutical Schedule, which lists about 1850 drugs eligible for subsidy through its PHARMAC program, defined by efficacy, cost and appropriate use. For example, to encourage quality use, a drug is covered only when used for a certain diagnosis. ${ }^{26}$ However, despite these provisions, New Zealand regularly faces medicine shortages; the list helps to manage them. ${ }^{27}$

In 2011, a team of 10 French internists, all working in hospitals, generated a list of 100 essential medicines from a potential total of 4600 . Beyond demonstrating the feasibility of the exercise, they were encouraged that the list included a majority of affordable generics and covered $95 \%$ of pathologies, once again 
contributing to cost control and quality use. They hope to expand the list with input from general practitioners. ${ }^{28}$

Although many of these programs in developed countries originated to control costs of subsidized drugs, they are beginning to demonstrate advantages in managing shortages and in ensuring quality of care.

\section{What are important barriers to implementation?}

Initially, pharmaceutical companies and a few physician groups criticized the essential medicines list project because it favoured generic products and appeared to challenge professional autonomy. ${ }^{3}$

Controversy still surrounds the health consequences of drugs and devices being subject to the Agreement on Trade-Related Aspects of Intellectual Property Rights (TRIPS), adopted in 1995 to safeguard patent rights, and subsequent trade agreements. ${ }^{29}$ Essential medicines lists were meant to serve as a guide to remedies that might qualify for TRIPS exemptions through a 2003 waiver for compulsory licences to sell needed drugs in countries that did not manufacture them. But only one company (Apotex, in Canada) ever attempted to bring forward a remedy under this scheme: an antiretroviral combination for Rwanda. ${ }^{30}$ The experiment was judged a failure, and essential medicines lists have yet to have an impact in shaping trade agreements on drug-related intellectual property.

\section{Do essential medicines lists reduce drug shortages?}

It is clear that essential medicines lists cannot be the sole protection against global drug shortages, because access to effective medicines depends not only on their identification and national purchasing power, but also on global availability. Since 2010, shortages of drugs have been frequent and often of long duration across the medical spectrum and on a global scale..$^{31-35}$ Surveys in Europe, ${ }^{36-38}$ the United States $^{39}$ and Canada ${ }^{40,41}$ suggest that the problem is persistent and widespread in developed nations. Reports from WHO and the media identify similar problems in many other countries. ${ }^{43,43}$ Since 2012, the US Food and Drug Administration and the US Government Accountability Office have been tracking the shortages; recent reports show that the shortages continue unabated. ${ }^{44}$
More than being an annoyance, drug shortages are dangerous and have even led to deaths. ${ }^{45,46}$ Children with controlled epilepsy have recurrence of seizures when obliged to take substitutes. People with cancer have ideal chemotherapy protocols interrupted or stopped. Surgeries are cancelled for lack of anesthetic. Those with chronic ailments are obliged to return to the pharmacy every few days to obtain their share of a rationed resource. Adverse effects that are sometimes devastating and permanent result from second- and third-line treatments. Notwithstanding Canada's reporting website, maintained by industry (www.drugshortages.ca), no annual or monthly tallies are being recorded in this country and no reports assess the extent or nature of the problem. On Feb. 10, 2015, Health Canada announced a plan for mandatory early notification from manufacturers of upcoming shortages (a step that the US took in October 2011); it has not yet been enforced. Itemized shortages are listed on the website, often just as, or even after, they occur, rarely in advance; and shortages are not analyzed in terms of frequency or type of drug.

The shortage of some off-patent drugs has been linked to particularly low reimbursement prices paid by hospitals and outpatient drug plans. ${ }^{47}$ If prices are below production and distribution costs, then manufacturers will not produce. But even when prices cover these costs, manufacturers might not prioritize production or invest in spare manufacturing capacity if prescribing volumes and profits are small.

Responses to drug shortages have included hoarding, gray-marketing and purchasing of temporary supplies at $650 \%-1400 \%$ markup from the original cost that results in a winnertakes-all bidding war between individual hospitals and countries. ${ }^{48,49}$ Mandatory reporting were it to be enforced - might help to reduce such practices. However, a process of identifying priority medicines and taking global collective action to address supply chain problems with contingency plans would arguably be more important.

\section{What could be gained by developing a Canadian essential medicines list?}

There are more than 8000 actively licensed drugs in the Canadian national pharmacopeia. Establishing an essential medicines list of perhaps 500 items could go a long way to ensuring availability of at least one drug for each health need encountered in ambulatory and inpatient settings. 
An essential medicines list could also underpin a national drug plan for pharmacare by identifying the essential medications that must be insured, ${ }^{50-52}$ that is, the minimum set of drugs that would be publicly funded for all Canadians. Such a step would support the recommendations on "better value from procurement, reimbursement and regulation" of the 2015 Report of the Advisory Panel on Healthcare Innovation. ${ }^{53}$ The development of an essential medicines list for this purpose would encourage innovation and study of how "wise lists" were generated in other developed nations. Some important questions require answers. Would large health facilities be invited to generate lists of their most frequently prescribed medications? Would the federal government negotiate with drug companies over the prices that will induce them to supply, much in the same way that they do for vaccines? Would there be a physical stockpile that could be accessed in case of supply disruption?

An essential medicines list, by itself, cannot solve the problem of shortages. Strong political action is needed to support creation of a Canadian essential medicines list both as a way to support national pharmacare and to support coordinated global efforts to mitigate drug shortages.

\section{What action is needed?}

No specific action has been taken after repeated calls for an essential medicines list in Canada, despite recent and past Canadian recommendations $^{2,54}$ and those made in other prosperous jurisdictions, including Australia in $2011^{55}$ and the US in $2013 .{ }^{56}$ Canada, with Alberta Health, already assembled many of the key stakeholders for drafting an essential medicines list when it generated its Multi-Stakeholder Toolkit in 2013, a document designed to explain drug shortages that has had little impact so far. ${ }^{57}$ These stakeholders could form a standing task force to work on creating Canada's first essential medicines list with input from pharmacists, specialist and family physicians, manufacturers and patient support groups. ${ }^{58}$

Canada has greater purchasing power than most nations that currently use essential medicines lists, but it is in a position to develop its own list in a unique fashion, learning from successes of other nations and adapting their strategies to its needs.

\section{References}

1. Essential medicines selection. National medicines list/formulary/ standard treatment guidelines. Geneva: World Health Organization. Available: www.who.int/selection_medicines/country lists/en (accessed 2016 Mar. 20)
2. Drug supply in Canada: a multi-stakeholder responsibility: report of the Standing Committee on Health. Ottawa: House of Commons; June 2012. Available: www.parl.gc.ca/content/hoc/ Committee/411/HESA/Reports/RP5640047/hesarp09/hesarp09 -e.pdf (accessed 2016 Mar. 20).

3. Laing R, Waning B, Gray A, et al. 25 years of the WHO essential medicines lists: progress and challenges. Lancet 2003;361: 1723-9.

4. Holloway KA, Henry D. WHO essential medicines policies and use in developing and transitional countries: an analysis of reported policy implementation and medicines use surveys. PLoS Med 2014;11:e1001724.

5. Declaration of Alma-Ata. In: International Conference on Primary Health Care; 1978 Sept. 6-12; Alma-Ata, USSR. Washington (DC): Pan American Health Organization and World Health Organization; 1978. Available: www1.paho.org/English/ DD/PIN/alma-ata_declaration.htm (accessed 2016 Mar. 20).

6. Hogerzeil HV, Samson M, Casanovas JV, et al. Is access to essential medicines as part of the fulfilment of the right to health enforceable through the courts? Lancet 2006;368:305-11.

7. Hill S, Yang A, Bero L. Priority medicines for maternal and child health: a global survey of national essential medicines lists. PLoS One 2012;7:e38055.

8. Magrini N, Robertson J, de Joncheere K, et al. On WHO's essential medicines process and transparency. BMJ 2014;349:g5637.

9. Nash DB, Catalano ML, Wordell CJ. The formulary decisionmaking process in a US academic medical centre. Pharmacoeconomics 1993;3:22-35.

10. Bazargani YT, Ewen M, de Boer A, et al. Essential medicines are more available than other medicines around the globe. PLoS One 2014;9:e87576.

11. Hill S, Henry D. National medicinal drug policies: their relationship to pharmacoepidemiology. In: Strom BL, editor. Pharmacoepidemiology. 4th ed. Chichester (UK); Hoboken (NJ): Wiley \& Sons; 2005. p. 377-90.

12. Hogerzeil HV, Walker GJ, Sallami AO, et al. Impact of an essential drugs programme on availability and rational use of drugs. Lancet 1989;1:141-2.

13. Essential Drugs Monitor No. 027: South Africa: getting essential medicines to the people. Geneva: World Health Organization; 1999. Available: http://apps.who.int/medicinedocs/en/d/ Jh1467e/2.3.html\#Jh1467e.2.3 (accessed 2016 Mar. 20).

14. Younis MZ, Hamidi S, Forgione DA, et al. Rational use effects of implementing an essential medicines list in West Bank, Palestinian Territories. Expert Rev Pharmacoecon Outcomes Res 2009:9:243-50.

15. Chaudhury RR, Parameswar R, Gupta U, et al. Quality medicines for the poor: experience of the Delhi programme on rational use of drugs. Health Policy Plan 2005;20:124-36.

16. Manikandan S, Gitanjali B. National list of essential medicines of India: the way forward. J Postgrad Med 2012;58:68-72.

17. Rico-Alba I, Figueras A. The evolution of Reference Drug Lists and Clinical Practice Guidelines in the public health system of a middle-income country. Br J Clin Pharmacol 2014; 78:410-21.

18. Barber SL, Huang B, Santoso B, et al. The reform of the essential medicines system in China: a comprehensive approach to universal coverage. J Glob Health 2013;3:010303.

19. Fang $\mathrm{Y}$, Wagner AK, Yang S, et al. Access to affordable medicines after health reform: evidence from two cross-sectional surveys in Shaanxi Province, western China. Lancet Glob Health 2013;1:e227-37.

20. Jøldal B. The evaluation and control of drugs in Norway. Int $J$ Technol Assess Health Care 1986;2:663-71.

21. Norway. Reimbursement list. Geneva: World Health Organization; 2011. Available: http://apps.who.int/medicinedocs/documents/ s19448no/s19448no.pdf (accessed 2016 Mar. 20).

22. An introduction to the pharmaceutical benefits scheme. Medicines Partnership of Australia; 2014. Available: http://medicines partnership.com.au/files/2013/02/20140224-gra-final-WEB -version-of-MA_PBS-booklet.pdf (accessed 2016 Mar. 20).

23. The Swedish Pharmaceutical Reimbursement System. Soln (Sweden): Pharmaceutical Benefits Board; 2007. Available: www.tlv.se/Upload/English/ENG-swe-pharma-reimbursement -system.pdf (accessed 2016 Mar. 20).

24. Gustafsson LL, Wettermark B, Godman B, et al. The 'wise list' - a comprehensive concept to select, communicate and achieve adherence to recommendations of essential drugs in ambulatory care in Stockholm. Basic Clin Pharmacol Toxicol 2011;108:224-33.

25. Fact Sheet \#7. Managing Medicines Supply. Wellington (New Zealand): Pharmaceutical Management Agency; 2016. Available: www.pharmac.govt.nz/assets/factsheet-07-managing -medicine-supply.pdf (accessed 2016 Mar. 20) 
26. August 2012: New Zealand Pharmaceutical Schedule. Wellington (New Zealand): Pharmaceutical Management Agency; 2012. Available: http://apps.who.int/medicinedocs/documents/ s19465en/s19465en.pdf (accessed 2016 Mar. 20).

27. Lee B. When the medicines run out: dealing with drug shortages. New Zealand Doctor. 2016 May 25.

28. Thomas M, Arlet P, Aumaitre O, et al. [100 essential drugs. An internal medicine approach]. Rev Med Interne 2013;34:460-4.

29. Wiley E, Hornung T, Hall DV, et al. Negotiating away health? Legal and ethical implications of the Trans Pacific Partnership (TPP) and the Trans Atlantic Trade \& Investment Partnership (TTIP). Proceedings of the UNESCO Chair in Bioethics $10^{\text {th }}$ World Conference on Bioethics, Medical Ethics and Health Law; 2015 Jan. 6-8; Jerusalem (Israel). ISAS International Seminars (Israel): United Nations Educational, Scientific and Cultural Organization; 2015. p. 75. Available: www.isas.co.il/ bioethics2015/Ethics_Book.pdf (accessed 2016 Mar. 20).

30. Submission to the Standing Committee on Industry. Science and Technology. Toronto: Apotex Inc.; 2010 Oct. 26. Available: www.apotex.com/global/docs/submission_order_en.pdf (accessed 2016 Mar. 20).

31. Jagsi R, Spence R, Rathmell WK, et al. Ethical considerations for the clinical oncologist in an era of oncology drug shortages. Oncologist 2014;19:186-92.

32. Griffith MM, Gross AE, Sutton SH, et al. The impact of antiinfective drug shortages on hospitals in the United States: trends and causes. Clin Infect Dis 2012;54:684-91.

33. Mazer-Amirshahi M, Pourmand A, Singer S, et al. Critical drug shortages: implications for emergency medicine. Acad Emerg Med 2014;21:704-11.

34. Fox ER, Sweet BV, Jensen V. Drug shortages: a complex health care crisis. Mayo Clin Proc 2014;89:361-73.

35. Duffin J. Drug shortage: recent history of a mystery. CMAJ 2012;184:1000.

36. Bogaert P, Bochenek T, Prokop A, et al. A qualitative approach to a better understanding of the problems underlying drug shortages, as viewed from Belgian, French and the European Union's perspectives. PLoS One 2015;10:e0125691.

37. McCartney M. Daily drug shortages place avoidable pressure on primary care. BMJ 2015;350:h2514.

38. Medicines shortages in European hospitals: the evidence and case for action. European Association of Hospital Pharmacists; October 2014. Available: www.eahp.eu/sites/default/files/ shortages_report05online.pdf (accessed 2016 Mar. 20).

39. Report to Congress: first annual report on drug shortages for calendar year 2013. Silver Spring (MD): US Food and Drug Administration; 2014 Feb. 5. Available: www.fda.gov/downloads/Drugs/ DrugSafety/DrugShortages/UCM384892.pdf (accessed 2016 Mar. 20).

40. Backgrounder drug shortages survey, January 2013. Ottawa: Canadian Medical Association, Canadian Society of Hospital Pharmacists, and Canadian Pharmacists Association; 2013. Available: www.pharmacists.ca/cpha-ca/assets/File/Drug ShortagesSurveyBackgrounder2013ENG.pdf (accessed 2016 Mar. 20).

41. Hall R, Bryson GL, Flowerdew G, et al. Drug shortages in Canadian anesthesia: a national survey. Can J Anaesth 2013; 60:539-51.

42. Gray A, Manasse HR. Shortages of medicines: a complex global challenge. Bull World Health Organ 2012;90:158 $158 \mathrm{~A}$.

43. Canadian drug shortage. Media reports. Available: www.canada drugshortage.com/media-reports (accessed 2016 Mar. 20).

44. Report to congressional addressees. Drug shortages: public health threat continues, despite efforts to ensure product availability. Washington (DC): Government Accountability Office; 2014 Feb. 10. Available: www.gao.gov/assets/670/660785.pdf (accessed 2016 Mar. 20)
45. Metzger ML, Billett A, Link MP. The impact of drug shortages on children with cancer - the example of mechlorethamine. N Engl J Med 2012;367:2461-3.

46. Meningitis outbreak exposes need to stop drug shortages. New York City: Bloomberg View; 2012 Oct. 23. Available: www. bloombergview.com/articles/2012-10-23/meningitis-outbreak -exposes-need-to-stop-drug-shortages (accessed 2016 Mar. 20).

47. Born K, Petch J, Dhalla I. Medication shortages: how Ontario came to rely on one manufacturer. Toronto: Healthy Debate; 2012 Apr. 19. Available: http://healthydebate.ca/2012/04/topic/ politics-of-health-care/medication-shortages-how-ontario-came -to-rely-on-one-manufacturer (accessed 2016 Mar. 20).

48. Arnold S. Cancer drug to be available again soon. Hamilton Spectator 2014 July 18.

49. Greene JA, Anderson G, Sharfstein JM. Role of the FDA in affordability of off-patent pharmaceuticals. JAMA 2016;315: 461-2.

50. Lewis S. A system in name only - access, variation, and reform in Canada's provinces. N Engl J Med 2015;372:497500 .

51. Morgan SG, Law M, Daw JR, et al. Estimated cost of universal public coverage of prescription drugs in Canada. CMAJ 2015; 187:491-7.

52. Morgan SG, Martin D, Gagnon MA, et al. Pharmacare 2020: The future of drug coverage in Canada. Vancouver: Pharmaceutical Policy Research Collaboration, University of British Columbia; 2015 July15. Available: http://pharmacare2020.ca/assets/pdf/ The_Future_of_Drug_Coverage_in_Canada.pdf (accessed 2016 Mar. 20).

53. Naylor CD, Girard F, Mintz J, et al. Appendix 1: List of recommendations. In: Unleashing innovation: excellent healthcare for Canada. Report of the Advisory Panel on Healthcare Innovation. Ottawa: Health Canada; July 2015. Available: www.healthycanadians.gc.ca/publications/health-system-systeme -sante/report-healthcare-innovation-rapport-soins/index-eng.php \#app1 (accessed 2016 Mar. 20).

54. Hollis A, Law S. A national formulary for Canada. Canadian Public Policy / Analyse de Politiques 2004;30:445-52.

55. Quilty S, Harris LM, Kewley J, et al. A Pandora's box: sustainable pharmaceutical supply. Med J Aust 2011;195:510-1.

56. 2013 drug shortages summit report: evaluating long-term solutions. Bethesda (MD): American Society of Health-System Pharmacists; 2013 Apr. 18. Available: www.ashp.org/DocLibrary/ Policy/DrugShortages/April-2013-Drug-Shortages-Summit-Report -Evaluating-Long-Term-Solutions.pdf (accessed 2016 Mar. 20).

57. A toolkit for improved understanding and transparency of drug shortage response in Canada. Multi-Stakeholder Steering Commitee on Drug Shortages; 2013. Available: www.drugshortages. ca/CMFiles/MSSC_Multi-Stakeholder_Toolkit_EN.FINAL. pdf (accessed 2016 Mar. 20).

58. Tierney M, Manns B; Members of the Canadian Expert Drug Advisory Committee. Optimizing the use of prescription drugs in Canada through the Common Drug Review. CMAJ 2008; 178:432-5.

Affiliations: School of Medicine (Eom), Queen's University, Kingston; Leslie Dan Faculty of Pharmacy (Grootendorst), University of Toronto, Toronto, Ont.; Hannah Chair, History of Medicine (Duffin), Queen's University, Kingston, Ont.

Contributors: All of the authors wrote and revised the article, gave final approval of the version to be published and agreed to act as guarantors of the work.

Acknowledgements: The authors acknowledge Dr. Beate Huber in Bonn, Germany; Dr. Anne Kveim Lie in Oslo, Norway; and Professor Arthur Sweetman, McMaster University. 